\title{
O OLHAR PSICANALÍTICO DE JANE CONNELL SOBRE O ENIGMA DE ÉDIPO E A ESFINGE
}

\author{
THE PSYCHOANALYTICAL LOOK OF JANE CONNELL \\ ON THE ENIGMA OF THE SPHINX AND OEDIPUS
}

\author{
Rafael Dotto Scremin \\ Universidade Federal de Santa Maria, Santa Maria, RS, Brasil
}

Resumo: A Esfinge de Tebas não é enigmática apenas por meio de suas palavras. A própria representação da Esfinge foi interpretada de diferentes formas ao longo do século XIX e XX. Recentemente, Jane Connell, psicanalista australiana, em "O Silêncio da Esfinge: O Erro de Édipo e a Redescoberta Resposta ao Enigma”, ao considerar a Esfinge uma personagem que possui gênero e posição subjetiva, questiona o olhar ocidental sobre o sujeito feminino. Pretende-se, com o presente artigo, revisitar alguns conceitos psicanalíticos referenciados pela autora, afim de contribuir para a interpretação da sua leitura sobre a personagem do mito. Em um segundo momento, os conceitos revisitados serão discutidos em nossa análise do mito

Palavras-Chave: Esfinge, Psicanálise, Feminino

Abstract: The Sphinx of Thebes is not only enigmatic in her words. The Sphinx itself has been interpreted in different ways throughout the nineteenth and twentieth century. Recently, Jane Connell, an Australian psychoanalyst, in "The Silence of the Sphinx: Oedipal error and the recovered answer to the riddle", by considering the Sphinx a character who has gender and subjective position, questioned the Western glance at the feminine character. In this article, we intend to revisit some psychoanalytic concepts referenced by the author in order to contribute to the interpretation of his reading about the sphinx in greek myth. In a second moment, the concepts will be revisited intertwined in our study of the myth.

Keywords: Sphinx, Psychoanalysis, Feminine

\section{Introdução}

$\mathrm{O}$ artigo de Jane Connell, intitulado "O Silêncio da Esfinge: $\mathrm{O}$ Erro de Édipo e a Redescoberta Resposta ao Enigma”, seria de grande valia se apenas observasse possíveis "lacunas" quanto às interpretações feitas ao longo da história em relação ao enigma proposto pela Esfinge tebana a Édipo. Acontece que, mais do que isso, sua tese é audaciosa ao afirmar que Édipo errou a resposta ao enigma (ou acertou parcialmente), e arrebatadora, por "redescobrir a resposta" naquela que possui apenas "uma voz", na mulher. É por meio deste tema que Connell faz uma crítica ao olhar do homem ocidental, representado por Édipo e Freud, sobre a figura do feminino apontando a sua opressão em relação ao desejo da mulher. Jane Connell defende que houve uma denegação por parte de Édipo e de Freud em relação ao feminino. Mas, o que precisamente isso quer dizer? O que o criador da psicanálise não quis ver? 
O presente artigo não tem o objetivo de desmembrar os conceitos psicanalíticos pormenorizadamente, mas apenas fazer com que possam ser assimilados em seu aspecto mais geral, o que, a nosso ver, enriquece a compreensão da proposta de Jane Connell. Para tanto, faremos uma explanação do conceito de Complexo de Édipo, cuja estruturação acompanha o nascimento da psicanálise, passando, indubitavelmente, pelo Complexo de Castração para, em seguida, cruzarmos tais apontamentos com o texto de Connell, bem como darmos ferramentas para se pensar a denegação de Freud em relação ao feminino.

\section{Os Conceitos Psicanalíticos utilizados por Connell}

Em "Três Ensaios Sobre a Teoria Sexual", de 1905, Freud começa a pensar a sexualidade infantil, cuja teoria recebe diversas reformulações ao longo de sua obra. Dessa forma, podemos encontrar a discussão sobre este tema, e indubitavelmente sobre o Complexo de Édipo, em textos como "O Eu e o Isso", de 1923, "A dissolução do Complexo de Édipo", de 1924, "Algumas consequências psíquicas da diferença anatômica entre os sexos", de 1925.

O Complexo de Édipo é popularmente conhecido como a fase em que a criança sente amor pelo progenitor do sexo oposto e ódio pelo progenitor do mesmo sexo. Entretanto, se fosse apenas isto, não teria sentido Connell dizer ironicamente que "o fato do feminino ainda não ter sido seriamente adaptado aos ditames do desenvolvimento do esquema edipiano não prejudica a influência dominante do complexo [de Édipo]" (2014, p. 45). É preciso ter em mente, antes de mais nada, que algo acontece antes da triangulação edípica (pai-mãe-bebê), no chamado período pré-edipiano. Quando a criança nasce ela está em simbiose com a mãe, isto é, na relação mãe-bebê, na qual a mãe investe seu desejo na criança, o que a faz um produto do inconsciente do Outro.

Nesse processo, pode-se afirmar que simbolicamente a criança "veste a máscara" do falo que a mãe não tem. Isso significa dizer, respectivamente, que é preciso, para a criança constituir-se como sujeito desejante, alguém inicialmente "desejar por ela", e que a criança representa para mãe uma espécie de "completude" - daí o termo "simbiose". Em um determinado momento, porém, um terceiro elemento, o pai (a Lei) se põe entre a mãe e o bebê, o que barra o acesso à satisfação naturalmente procurada. Aqui se iniciam os desejos amorosos e hostis que a criança nutre pelos pais, características centrais do que viria a chamar-se, em psicanálise, de Complexo de Édipo.

Durante sua auto-análise, e ao longo da análise de seus pacientes, Freud reconhece em si o amor pela mãe e um sentimento ambíguo de ciúme e afeição ao pai. Dessa forma, ele passa a estruturar o Complexo de Édipo, cujo apogeu se dá na fase fálica (entre os três e cinco anos), em torno da figura do 
menino, afirmando imediatamente a universalidade da sua teoria, cuja imagem está no mito grego de Édipo-Rei - aquele que mata o pai e se casa com a mãe - afirmando: "A todo ser humano é imposta a tarefa de dominar o Complexo de Édipo" (apud LAPLANCHE E PONTALIS, 2001, p. 77). Essa tarefa a que Freud se refere basicamente pode ser compreendida com a recusa ao incesto e a identificação com o progenitor do mesmo sexo, o que demarca o declínio do Complexo de Édipo. Logo, para o menino, temos que o objeto de amor não muda desde a sua relação simbiótica com a progenitora até o período edipiano: é à mãe que ele deseja o amor. Por outro lado, para a menina, que na fase préedipiana também tinha a mãe como objeto de amor, irá mudar, no Complexo de Édipo, para o pai. Ora, fica evidente, então, que há uma diferença na entrada do Complexo de Édipo para a menina - tal complexo não pode ser transposto para ela tal e qual se dá para o menino. Temos aqui que o fim do período edipiano para o menino e o início do mesmo período para a menina têm relação com o Complexo de Castração.

Segundo Laplanche e Pontalis, o complexo de Castração é "centrado na fantasia de castração, que proporciona uma resposta ao enigma que a diferença anatômica dos sexos (presença ou ausência de pênis) coloca para a criança" (2001, p. 73). A justificativa para que tal complexo se dê para os dois sexos está na "primazia do falo", uma vez que, durante a fase fálica não se tem o reconhecimento de um órgão genital masculino e de outro feminino: ou se tem o falo, ou se perdeu o falo. A relação, portanto, não é masculino-feminino, mas sim fálico-castrado. É preciso observar que "falo" não diz respeito a "pênis". Falo é o termo que "sublinha a função simbólica desempenhada pelo pênis na dialética intra e intersubjetiva" (LAPLANCHE E PONTALIS, 2001, p. 166), ou seja, ele é significante, ele "dá nome" ao desejo - "se tenho, não quero perder"; "se não tenho, quero ter". O pênis acaba apenas por ser o órgão fálico por excelência porque a criança, ao descobrir que o corpo da mãe é desprovido de pênis, faz dele o falo número um das representações imaginárias (KEHL, 2008). O falo, então, por obturar esta falta materna, se faz presente ao mesmo tempo em que se dá a dimensão da falta. Eis o motivo do porquê de ter o falo não significar estar protegido da castração, do mesmo modo que não ter o falo não significa que nunca se terá a posse dele (a sedução, por exemplo, é um recurso para se produzir falicidade).

Se no menino, então, a castração aparece como uma ameaça paterna em resposta às suas atividades sexuais, isto demarca a recusa ao incesto e a identificação com o pai, marcando o final do Complexo de Édipo de maneira abrupta. Por outro lado, na menina, ela culpa a mãe pela ausência do pênis, sendo este um dano sofrido que ela procura negar, compensar ou reparar, e isto acontece com a mudança do objeto de amor da mãe para o pai, para aquele que tem e que pode lhe dar o falo. Dessa forma, o Complexo de Castração na menina demarca a sua entrada no Complexo de Édipo. O fim 
deste período para a menina se dá quando ela renuncia ao pênis, após uma tentativa de compensação, manifesta no desejo de dar à luz a um filho de seu pai (possuidor do falo), cujo bebê, por equivalência simbólica, estaria no lugar do pênis a ser recuperado. Isso torna inconcluso o momento do declínio do complexo na menina, o que é criticado por Jane Connell na medida em que aponta para a falta de esclarecimentos sobre o tema.

Do surgimento ao desaparecimento do Complexo de Édipo, tem-se a estruturação das instâncias psíquicas do sujeito: Isso (Es, ou Id), Eu (Ich, ou Ego), Supereu (Über-Ich, ou Superego). O Isso, que está relacionado diretamente ao Inconsciente, predomina durante o período pré-edipiano, no qual há a simbiose mãe-bebê. Logo, o indivíduo atende desenfreadamente às exigências do Inconsciente, no qual o incesto é permitido. $\mathrm{Na}$ triangulação edípica mãe-pai-bebê, a Lei paterna barra a realização desenfreada de desejo, e a instância psíquica Eu deve administrar as pretensões do Isso. Ao final do Complexo de Édipo, herdeiro da Lei paterna, instaura-se o Supereu, que atua como um "censor". Temos assim, a constituição de um sujeito estruturado (Isso, Eu, Supereu), que compreende não poder assumir o lugar do pai e tampouco ter a mãe para si. Por isso, o sujeito formado procura substitutos para as pulsões sexuais dando início à vida social, regrada pelo Supereu. Esta fase é denominada de período de Latência, que se estende do final do Complexo de Édipo até o início da transição para a vida adulta. É durante este período que o ser age como uma "esponja" que absorve e lida com os aspectos culturais do meio em que está inserido, construindo assim a estrutura de sua "casa"15, isto é, de local de aprendizagem e preparação para a vida adulta.

Após alguns anos de "estabilidade psíquica", é preciso deixar o lar, devido à reedição do Complexo de Édipo, que ocorre por motivos biológicos e psíquicos. O sujeito tem o corpo, além de transformado biologicamente, apto para o exercício da vida sexual, encontrando-se com o Real ainda não simbolizado, isto é, há uma estranheza quanto ao seu aspecto físico, que ainda não foi assimilado de todo pelo psíquico. Esse é um dos motivos por buscar a si mesmo fora da casa, como que na procura por aqueles que estejam passando pelo mesmo processo de transformações. Esta busca, no entanto, além de conter o despertar da sexualidade, implica no encontro com o outro alter, ou seja, aquele que se apresenta enquanto alteridade, que é diferente, com existência própria. A alteridade do outro é aquilo que chega como desconhecido, cujo encontro Jane Connell chama de "crise existencial" (2014, p. 70). É neste ponto que ocorre a reedição do Complexo de Édipo, agora com a sexualidade voltada quase que exclusivamente aos órgãos genitais, ao encontro com o outro. Ora, fica evidente, então, a saída de casa: os objetos

15 A partir daqui, todas as referências à "casa", enquanto o espaço psíquico do sujeito, estão baseadas no artigo "Toxicomania e adolescência: a transgressão do mito do herói”, de Fabio Massao Yabushita. 
primários da infância retornam (pai e mãe), com a diferença de que, agora, a concretização do incesto, mais do que nunca, é de fato possível, seja pela maturação corporal, seja pela capacidade de enfrentar a Lei paterna.

O sujeito em processo de maturação precisa encontrar um outro que se ponha no lugar da mãe, para evitar o incesto. Da mesma forma que ele busca "outra mãe", busca também "outro pai". Isso significa dizer que uma nova autoridade - pensemos nos ídolos da adolescência - com a qual o sujeito se identifica vai de encontro a Lei paterna, para que se possa contestá-la e "fugir de casa". Agora, fora de casa, o adolescente precisa encontrar uma nova forma de organização psíquica, e, por isso, o grupo social (as "tribos", por exemplo) ocupa o lugar do grupo familiar. Neste novo ambiente, porém, atualiza-se um familiar desafio: resolver o impasse que surge com a constatação da diferença anatômica entre os sexos.

O sexo oposto possui uma alteridade tal que não complementará de fato o sujeito, que, indubitavelmente, percebe-se um ser faltante. Ora, homemmulher, masculino-feminino, masculinidade-feminilidade são relações dialéticamente necessárias para que cada um faça sentido para si próprio. Todavia, para tanto, eles precisam estar pareados; não se trata de pares opostos complementares, daí Lacan ter dito que "não existe relação sexual", porque não é possível que de dois se faça um (KEHL, 2008). Do contrário, estaríamos dizendo que o homem é o sujeito do desejo, por ser possuidor do falo, e a mulher é o objeto do desejo, por ser possuidora da "falta". Como o homem e a mulher são sujeitos do desejo, passamos a perceber que a dialética não se dá entre aquele que possui o falo e aquele que não o possui, mas sim entre quem não tem o falo e quem pode perdê-lo (lembremos aqui da ameaça de castração). Compreender a dimensão da falta é fundamental para se perceber a relação do sujeito com o seu desejo. Afinal, é a partir de uma falta que o desejo se produz - se deseja aquilo que não se tem ou que não se quer perder. Se o ser humano é o único animal que possui desejo, então é ele quem media a vida social dos sujeitos em relação aos seus objetos desejados.

Perceber e aceitar esta falta que recai sobre si é condição para que o sujeito não procure a satisfação dos seus desejos de forma narcísica e onipresente, ou seja, para que ele não retorne ao leito familiar como o filho que retorna à casa, mas sim como sujeito desejante. Ele precisa, para isso, aceitar a alteridade do outro, precisa perceber-se não-todo, para que, na relação dialética com outro alter, transmute uma nova percepção de si e do outro. A alteridade do outro deve impedir a satisfação narcísica do sujeito para que ele viva em sociedade reconhecendo este outro como sujeito, não apenas como objeto de desejo. Lidar, portanto, "com a frustração e a incompletude, simbolizando-as por meio da linguagem e do discurso subjetivo, é condição para retornar à casa" - é preciso responder corretamente o enigma. 
Assim, o sujeito ingressa no processo civilizatório, não regulando a sua vida na busca desenfreada pelo prazer, como outrora na infância, percebendo e construindo com o outro as exigências sociais. É, portanto, pela mediação entre o desejo e a proibição, novamente, realizada por um Eu que ele se fortalece a ponto de lidar com as demandas da realidade. A partir daqui, temos um rápido auxílio teórico para compreender as questões que seguem. Com a compreensão dos conceitos que teorizam sobre a formação da personalidade no sujeito, podemos nos permitir um outro olhar sobre as argumentações de Jane Connell.

\section{Para ver o que eles não viram}

Como Connell demonstra em "O Enigma de Freud: a pergunta errada", para Freud, a Esfinge pode ser o pai/homem ou uma criança, mas nunca uma mulher adulta que tem ciência de sua própria condição enigmática. Isso indica, segundo a sugestão da autora, que a personagem feminina, a Esfinge, é recalcada enquanto tal. Mais do que isso, que ocorre uma denegação na própria interpretação freudiana. Contudo, para compreender esse ponto, o da denegação de Freud, precisamos falar primeiro da Esfinge e de Édipo.

Quanto ao pensamento sobre a capacidade do enigma da Esfinge tebana proporcionar ou não um diálogo, temos uma curiosa observação de Connell: "talvez a alegação de que um enigma não pode ser resolvido indique a recusa em perceber a perspectiva de quem o profere (itálico nosso)" (2014, p. 50). A autora está falando, aqui, sobre a necessidade de um "olhar", não de um "ponto de vista". O ponto de vista de quem responde ao enigma é dado a partir de si mesmo, isto é, a dimensão do outro só é considerada a partir do que ele acha do outro. Nesse sentido, não há "escuta", as palavras proferidas por aquele que propõe o enigma são interpretadas por aquele que escuta a partir das imagens que ele faz a partir de si. Diferentemente dessa perspectiva, o "olhar" compreende a capacidade de que os envolvidos no diálogo, de certo modo, transponham as barreiras que limitam um a colocar-se no lugar do outro. Ter um olhar sobre quem fala, não diz respeito apenas à capacidade de se por no lugar do outro, mas, além disso, permitir que o outro tome um lugar naquele que escuta, ou seja, permitir que o outro seja sujeito de si mesmo.

Jane Connell, em "Quem é a Esfinge?" (2014, p. 50-53), nos demonstra que a Esfinge sempre esteve associada à morfologia do corpo, mas muito superficialmente com a complexidade do imaginário mitológico. Sua monstruosidade não apenas aponta para a marginalização da sua subjetividade, do seu contexto, da sua história, da sua posição discursiva, como também aponta para, quando pensando no sujeito feminino, no quanto a mulher está amarrada à representação imaginária do corpo. 
Sobre a origem dessa questão, Maria Rita Kehl (2008) sugere uma indiscriminação nos textos freudianos entre a dimensão imaginária e a dimensão simbólica do falo. Precisamos ter em mente, aqui, que a dimensão imaginária refere-se ao campo das imagens e, portanto, das Representações de Coisa, isto é, aquelas que não são "nomeadas", próprias do inconsciente; por outro lado, a dimensão simbólica refere-se ao campo da palavra, das Representações de Palavra. Logo, quando se tem certa indiscriminação entre a dimensão imaginária e a dimensão simbólica do falo, sugerimos que, diferente do homem, os efeitos posteriores da castração no sujeito feminino estarão atados à representação do corpo, uma vez que ela é a evidência imaginária da falta - é visível no corpo: ela não tem o pênis. Como consequência disso, as possibilidades fálicas para a mulher acabam por estarem atadas aos limites do corpo, enquanto ao homem é permitido buscar a falicidade no campo simbólico oferecido pela cultura - não nos deixemos esquecer que esta busca por falicidade é aquela busca pela "completude com a mãe", que perdemos com o atravessamento da Lei.

Tendo em vista o caminho percorrido pelo pensamento científico nos últimos séculos, desde o século XVIII, no qual a mulher é determinada pela sua pertença ao estado de natureza (da figura da mãe, de objeto de desejo), não é de se surpreender que também a psicanálise confirme as convalidações sociais que impedem a fantasia do falo de sofrer metamorfoses, para as mulheres, amarrando-o ao corpo (KEHL, 2008). Portanto, podemos, ainda que pretensiosamente, acrescentar ao pensamento de Connell, que a monstruosidade da Esfinge talvez seja um "sintoma" que nos faça pôr em questão os grilhões que prendem o sujeito feminino à representação do seu corpo, dos limites da sua imagem, e, justamente por este motivo, "limitandolhe" a condição de sujeito e sobrepondo à condição de objeto do desejo do outro. Quando respondemos ao enigma da Esfinge tebana, tal e qual Édipo, estamos tendo um "ponto de vista", não um "olhar" sobre o feminino.

Seguindo no texto de Connell, em "A Falha Trágica: a Heterossexualidade Socializada" (2014, p. 59-62), temos que, como autora disserta, a dinâmica das trocas, da subjetivação social, entre o homem e a mulher perturba a transformação do herói em anthropos, em humano, em homem. A questão aqui em xeque é o confronto discursivo entre Édipo e a Esfinge e a capacidade desse encontro representar uma passagem para a maturação do homem. A hipótese da autora é a de que Édipo passa da adolescência para a maturidade através de um confronto subjetivo e existencial em um cenário social não-estruturado. Cenário este que apresentaria uma mudança cultural quanto aos ritos de passagem, agora baseados na razão, no diálogo, entre os homens.

Como havíamos dito, o adolescente, durante a reedição do Complexo de Édipo, deixa a casa para buscar novas respostas para seu "conflito 
existencial", numa busca por si mesmo que culmina no encontro com a alteridade do outro. Vimos também que, se o sujeito não tiver o seu desejo barrado por este outro alter, se ele não reconhecer a si mesmo como sujeito faltante, ele tende a retornar às satisfações narcísicas e onipresentes da infância, ou seja, tende a retornar a casa antes de completar a sua formação em homem adulto, sujeito de si. Temos, então, que Édipo denega o feminino e retorna a casa, cujo final da história nos é sabido: toma a mãe por esposa. Nesse momento, acessamos ferramentas suficientes para entender não apenas a hipótese de "estase agorafóbica", a qual Connell se refere, mas também de que a denegação de Édipo é o que impede, não apenas que a Esfinge se faça presente enquanto sujeito, como também que o próprio herói tenha sucesso na entrada da maturidade.

A agorafobia, que tem a característica de se apresentar no final da adolescência e no início da vida adulta, como toda a fobia, segundo a psicanálise, tem uma natureza sexual. Por meio de uma rede complexa de representações que se associam, desde o objeto atual que causa a fobia até a sua origem, temos que, em última instância, o medo fóbico revela um motivo muito particular em cada sujeito, devido às inúmeras possibilidades de suas associações. Essa é a chamada Formação de Compromisso, um produto do conflito defensivo, que é uma forma de o recalcado vir à tona na forma de um sintoma, de um sonho, ou de outra produção do inconsciente na qual, por meio das representações associadas, uma representação se põe no lugar de outra a ponto de ser irreconhecível e, consequentemente, posta para fora do inconsciente (LAPLANCHE E PONTALIS, 2001). Assim, quando pensamos no retorno de Édipo ao leito familiar enquanto "sintoma" de uma "estase agorafóbica", pensamos em um sujeito que não suporta a alteridade do outro, que não se percebe um ser faltante, que evita a troca dialética a fim de retornar ao ambiente no qual já gozara da "completude do seio materno".

Mas o que causa esse "pavor", essa "crise existencial", como Connell denomina, que faz com que Édipo retorne ao núcleo familiar? Segundo Connell, a Esfinge é o outro alter, ela é quem possui a alteridade que faz com que quem se julgou dono do falo se perceba faltante, pois ela é uma mulher, aquela que traz consigo no corpo a marca da falta. É o fato de ser personagem feminina que causa a denegação, em Édipo e em Freud.

A denegação é a percepção e recusa de algo, ao mesmo tempo. Para entender este mecanismo, pensemos na estruturação do fetiche, que foi usada por Freud para explicar a perversão, tendo como consequência o estabelecimento final do caráter simbólico do falo. Segundo Freud, "o fetiche é o substituto do falo da mulher (no caso, a mãe), em cuja existência a criança pequena acreditou e ao qual não quer renunciar" (apud KEHL, 2008, p. 198), isto é, "o fetiche é o significante que vem obturar o lugar de uma falta percebida e recusada". Isso leva a pensar que a crença no falo feminino é a 
criação de um objeto-fetiche que se põe no lugar daquilo que falta no corpo da mãe (Ibidem, Idem). Por consequência, o estatuo fálico do pênis deixa de ter a soberania de antes: "o pênis só é o falo quando se constitui como objeto do desejo materno, isto é, objeto capaz de obturar a falta" (Ibidem, p. 199). Ter o pênis, portanto, não é garantia de pertença do falo: temos então, não a castrada e o fálico, mas aquela que não tem o falo, e aquele que tem mas pode perdê-lo.

Ademais, se a denegação propõe percepção e recusa da falta, o objeto fetiche é, ao mesmo tempo, amado e odiado, afinal, ele confirma e nega a castração do sujeito: "o fetichista mantém uma dupla atitude frente à castração no corpo da mulher: ele-sabe-mas-não-quer-saber" (2008, p. 199). Assim, segundo Maria Rita Kehl, o mistério da feminilidade não está na mulher, mas na estruturação do fetiche que organiza o desejo, e conclui este ponto com uma audaciosa provocação a Freud:

Deste ponto em diante, quando Freud se referir aos mistérios da mulher, devemos sempre nos indagar se ele está falando do lugar do observador analítico, ou se está identificado com o fetichista, aquele que sabe, mas não quer saber. (2008, p. 199)

A denegação de Freud, portanto, é a mesma de Édipo: diante daquela que lhes mostra a falta, é melhor fazer de conta que se viu, sim, alguma coisa, do contrário, ambos se admitirão faltantes, castrados. Ainda sobre o ponto enigmático do feminino, Maria Rita Kehl aponta:

A manutenção do ponto enigmático sobre o querer feminino, a representação da mulher como o continente negro da psicanálise, seriam a meu ver recursos a que Freud recorreu para manter-se ignorante a respeito do que ele mesmo não queria saber, embora já tivesse revelado ao resto do mundo: a diferença fundamental entre homens e mulheres é tão mínima, que não há mistério sobre o "outro" sexo que um cavalheiro não pudesse responder indagando a si próprio. $\mathrm{O}$ que fez Freud, aliás - mas como bom neurótico, não podia saber o que estava fazendo. (2008, p. 187) responde:

E, sobre, o "o que querem as mulheres?", Maria Rita Kehl, ainda,

Cada vez que um psicanalista, depois de Freud, sustentar que existe um ponto impossível de desvendar sobre o querer das mulheres, devemos the responder, como Sócrates: 'indaga-te a ti mesmo'... Pois só o que um homem recusa saber sobre o seu 
desejo é capaz de produzir o mistério sobre o objeto ao qual ele se dirige, o desejo de uma mulher. (2008, p. 14)

A partir da passagem supracitada, entendemos um mistério como algo produzido por uma recusa em ver/saber. Se pensarmos que a Esfinge tebana é considerada pelos homens ocidentais um mistério em si mesma, temos que há, aqui, um mecanismo de recusa por parte do seu intérprete. Mais do que isso, temos o que esta recusa diz do desejo do interlocutor da "monstruosa criatura"; logo, o "mistério" está em quem olha, não em quem é "olhado". Ao olharmos para a "proclamadora de enigmas" enquanto "criatura", não-mulher, somos como a criança que se recusa a ver na mãe aquela cujo ideal de completude simbiótica promoveu outrora o prazer desenfreado - a falta. Este é o ponto de Connel: ao olhar para a Esfinge nos confrontamos com a diferença sexual, que deve ultrapassar a diferenciação fálico-castrado para que não se tenha a opressão do homem sobre a mulher, isto é, para que se tenha a mulher enquanto sujeito, produtora de desejos inconscientes.

Em suma, para responder a pergunta, "o que quer uma mulher?", isto é, para que Édipo responda corretamente aquilo que a Esfinge talvez desejasse, é cabal perder o medo de se ter roubada a coroa de rei que nunca se teve. É preciso abrir-se à "crise existencial" de saber-se faltante, para se construir, no diálogo também com a mulher, uma sociedade em que o falo não seja o cajado de um homem opressor. Afinal, se a castração é condição para que se tenham representações, isto é, se é a partir da castração que o significante vem nomear aquilo que falta no outro (KEHL, 2008, p. 187), então temos que ela é a condição do estabelecimento de vínculos, pois faz laço com o outro, pondo, também, o falo ao alcance de todos. É preciso admitir-se faltante para se estabelecer vínculos sociais que não oprimam a mulher enquanto sujeito $-\mathrm{e}$, também no caso de Édipo e Freud - para não retornar ao leito familiar ou reescrever, no interior de suas alcovas, os enigmas das Esfinges.

\section{Conclusão: os homens, as mulheres}

Com a interpretação de Jane Connell, ver a Esfinge tebana enquanto uma personagem feminina traz consequências ainda mais profundas do que a relação desta personagem com o mito grego. Além de apontar para uma transformação na esfera social grega, do combate físico para o combate do diálogo, nos mostra que a relação do homem ocidental moderno com o feminino ainda traz consigo a catarse de uma tragédia grega. E isto é percebido pela autora através do discurso e, principalmente, pela ausência dele. Connell nos lembra o quão determinante é a língua para a estruturação psíquica e a posição social do sujeito. A afirmação do indivíduo como sujeito - não mais 
como o objeto - de desejo passa inexoravelmente pela linguagem e pela comunicação. Quando ambas falham, tem-se o dever ético de escutar o silêncio, de perceber no corpo aquilo que não foi traduzido pela boca.

Dizer "o homem" para nos referirmos à raça humana, como Édipo o fez, ao pensar responder ao enigma, não inclui a mulher. Não há A Mulher, enquanto conjunto que represente todas as mulheres, da mesma forma como não há $\mathrm{O}$ Homem, enquanto conjunto que represente todos os homens. Enquanto se admitir dois conjuntos, o do homem e o da mulher, a discussão sobre gênero estará atada ao corpo, e a consequência disto é a dominação de um sobre o outro. "Homem" e "mulher" são construções em constantes transformações, que se afirmam, necessariamente, na relação dialética de um com o outro, pois não se tratam de pares complementares. Cabe ao homem perceber o sujeito no outro sexo, da mesma forma como cabe à mulher afirmar a sua voz, a sua posição de sujeito desejante frente ao discurso do outro e o do seu próprio. Cabe ao homem e à mulher perceberem os homens, as mulheres, na sua pluralidade e, só então, na singularidade de cada sujeito.

Não olhar para a Esfinge enquanto personagem feminina, hoje, é não-querer ver a alteridade produzida pelo outro. É a arrogância do homem (e também da mulher) de se colocar frente aos sujeitos enquanto reis, reis de Tebas, encerrados na - falsa - comodidade de um abraço maternal.

Recebido em 28 de Setembro de 2013.

Aceito em 04 de Outubro de 2013.

\section{REFERÊNCIAS}

CONNELL, J.

KEHL, M. R., Deslocamentos do feminino. 2. ed. Rio de Janeiro: Imago, 2008

LAPLANCHE, J; PON TALIS, J.-B. Vocabulário da psicanálise. Trad:

Pedro Tamen. ${ }^{\text {a }}$. ed. São Paulo: Martins Fontes, 2001

YABUSHITA, F. M. Toxicomania e adolescência: a transgressão do

mito. Disponível em: <http://www.psicologiajunguiana.psc.br/page4.php>. Acesso em: 18 fev. 2014.

76 fragmentum, N. 38, Vol. 1. Laboratório Corpus: UFSM, Jul./ Set. 2013 